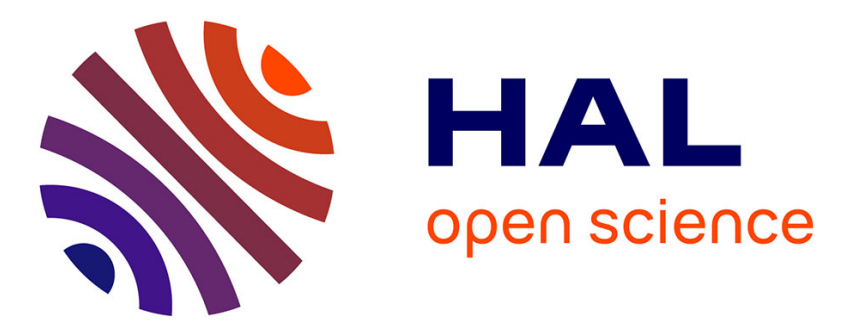

\title{
Aerobic oxidation catalyzed by polyoxometalates associated to an artificial reductase at room temperature and in water
}

\author{
Ahmad Naïm, Yoan Chevalier, Younes Bouzidi, Priyanka Gairola, Pierre \\ Mialane, Anne Dolbecq, Frédéric Avenier, Jean-Pierre Mahy
}

\section{To cite this version:}

Ahmad Naïm, Yoan Chevalier, Younes Bouzidi, Priyanka Gairola, Pierre Mialane, et al.. Aerobic oxidation catalyzed by polyoxometalates associated to an artificial reductase at room temperature and in water. Inorganic Chemistry Frontiers, 2020, 7 (12), pp.2362-2369. 10.1039/d0qi00442a . hal02945308

\section{HAL Id: hal-02945308 \\ https://hal.science/hal-02945308}

Submitted on 22 Sep 2020

HAL is a multi-disciplinary open access archive for the deposit and dissemination of scientific research documents, whether they are published or not. The documents may come from teaching and research institutions in France or abroad, or from public or private research centers.
L'archive ouverte pluridisciplinaire HAL, est destinée au dépôt et à la diffusion de documents scientifiques de niveau recherche, publiés ou non, émanant des établissements d'enseignement et de recherche français ou étrangers, des laboratoires publics ou privés. 


\title{
Aerobic Oxidation Catalyzed by Polyoxometalates Associated to an Artificial Reductase at Room Temperature and in Water
}

\author{
Ahmad Naim, ${ }^{a, b}$ Yoan Chevalier, ${ }^{a}$ Younes Bouzidi, ${ }^{a}$ Priyanka Gairola, ${ }^{a, b}$ Pierre Mialane, ${ }^{b *}$ Anne \\ Dolbecq, ${ }^{\mathrm{b}}$ Frédéric Avenier, ${ }^{\mathrm{a}}$ Jean-Pierre Mahy ${ }^{\mathrm{a}}$

\begin{abstract}
Four polyoxometalates (POMs) were combined with an artificial reductase based on polyethyleneimine (PEI) and flavin mononucleotide (FMN) which is capable of delivering single electrons upon addition of nicotinamide adenine dinucleotide (NADH). The efficiency of this system for sulfoxidation reactions in water, at room temperature, under atmospheric pressure and with dioxygen as an oxidant was demonstrated, with yields up to $82 \%$ in sulfoxide. Mechanistic investigations allowed proposing two different catalytic pathways, depending on the nature of the POM. For the polyoxotungstates $\mathrm{Na}_{12}\left[\left(\mathrm{ZnW}_{9} \mathrm{O}_{34}\right)_{2} \mathrm{WZn}_{3}\left(\mathrm{H}_{2} \mathrm{O}\right)_{2}\right] \cdot 46 \mathrm{H}_{2} \mathrm{O}$ and $\mathrm{Na}_{7} \mathrm{~K}_{7}\left[\left\{\left(\mathrm{PW}_{9} \mathrm{O}_{34}\right) \mathrm{Ni}_{3}(\mathrm{OH})\left(\mathrm{H}_{2} \mathrm{O}\right)_{2}(\mathrm{Ale})\right\}_{2} \mathrm{Ni}\right] \cdot 34 \mathrm{H}_{2} \mathrm{O}$ (Ale = alendronate = $\left.\left[\mathrm{O}_{3} \mathrm{PC}(\mathrm{O})\left(\mathrm{C}_{3} \mathrm{H}_{6} \mathrm{NH}_{3}\right) \mathrm{PO}_{3}\right]^{4-}\right)$, the in situ production of $\mathrm{H}_{2} \mathrm{O}_{2}$ by the artificial reductase that activates the POM was evidenced. Alternatively, for the polyoxomolybdates $\mathrm{H}_{3}\left[\mathrm{PMO}_{12} \mathrm{O}_{40}\right] \cdot 14 \mathrm{H}_{2} \mathrm{O}$ and $\mathrm{H}_{4}\left[\mathrm{PMO}_{11} \mathrm{VO}_{40}\right] \cdot 14 \mathrm{H}_{2} \mathrm{O}$, the reduction of the POM by the artificial reductase, followed by the reductive activation of $\mathrm{O}_{2}$, led to the sulfoxidation reaction.
\end{abstract}

\section{Introduction}

The majority of industrial chemical processes, such as oxidations, are based on harsh conditions (high temperature, pressure, corrosive oxidants and/or toxic solvents), leading to a harmful impact on the environment. ${ }^{1}$ It has therefore become essential, in the present context of sustainable growth, to develop new environmentally friendly chemical processes. ${ }^{2-7}$ There are different manners to reduce the impact of chemical processes on the environment and at least two key points have to be addressed: (i) to reduce energy consumption by lowering temperature and pressure, (ii) to reduce waste production by avoiding organic solvents and by improving the selectivity and the chemical yields. On the one hand, enzymes entirely fulfill these requirements, but unfortunately also require numerous steps of cloning, overexpression and purification, which strongly restricts their use in industrial processes. ${ }^{8}$ On the other hand, many of the chemical processes that are usually used are based on potentially harmful catalysts to the environment. ${ }^{9}$ Therefore, the development of bioinspired catalysts, mimicking enzymes activity, is a major challenge in order to take advantage of both enzyme specificity and robustness of handmade catalysts. ${ }^{10,11}$

Sulfoxidation is one of the most fundamental chemical reaction in organic synthesis as, for example, many sulfoxides and sulfones

\footnotetext{
a. LCBB, ICMMO, Univ Paris-Sud, Université Paris Saclay, rue du doyen Georges Poitou, 91405 Orsay, France.

b. Université Paris Saclay, UVSQ, CNRS, UMR 8180, Institut Lavoisier de Versailles, 45 Avenue des Etats-Unis, 78035 Versailles Cedex, France.

tElectronic Supplementary Information (ESI) available: detailed synthetic procedures, representation of the POMs and additional spectroscopic characterizations. See DOI: 10.1039/x0xx00000x
}

intermediates have been shown to be the active principals of several drugs. ${ }^{12}$ The oxidation of a sulfide (thioether) molecule can yield sulfoxide and/or sulfone products depending on the applied oxidation method, ${ }^{13}$ and many reagents are able to selectively form sulfoxide and/or sulfone adducts. However, they are usually based on toxic and corrosive oxidants such as peroxides, peracids, halogen or nitrogen-oxide derivatives. ${ }^{13-15}$ The main challenge is now to use dioxygen which represents a cheap, clean and readily available oxidant, notably used in nature by enzymes that perform oxidation reactions in aqueous solution and under mild conditions. In this respect, many catalytic oxidation reactions exist in the literature using dioxygen, but most of them use harmful catalysts and organic solvents under harsh conditions (high temperature or pressure). ${ }^{16-}$

${ }^{21}$ In contrast, nature has figured out an elegant manner to catalyze such reactions by reductive activation of molecular dioxygen. As a typical example, $\mathrm{O}_{2}$ reduction activation occurs at iron(II) centers present in multi-component enzymatic systems named iron monooxygenases. ${ }^{22-24}$ It should be underlined that while monooxygenases such as cytochromes $\mathrm{P} 450$ are able to activate dioxygen in order to selectively oxidize alkanes into alcohols, they require a steady and accurate input of electrons. These electrons are provided by an associated reductase, a flavoprotein that collects electron pairs from nicotinamide adenine dinucleotide (NADH) or nicotinamide adenine dinucleotide phosphate (NADPH) and delivers a single electron flow to the metallic active site of the enzyme thanks to its flavin adenine dinucleotide (FAD) and flavin mononucleotide (FMN) cofactors. The reductive activation of dioxygen at the iron center allows the formation of high-valent ironoxo species capable of transferring an oxygen atom into the $\mathrm{C}-\mathrm{H}$ bond of diverse substrates. ${ }^{25-27}$ Many efforts have been made to mimic flavoenzymes ${ }^{28-31}$ in order to deliver electrons accurately to metal catalysts but it has been proven very difficult to combine 
these reductive conditions with the formation of high valent ironoxo species. ${ }^{32}$ Consequently, most of the bio-inspired systems developed so far shunt this reduction process by the use of hydrogen peroxide. ${ }^{33-36}$ Also, the majority of other bio-inspired systems that are based on FMN have employed $\mathrm{H}_{2} \mathrm{O}_{2}$ as oxidant to catalyze the oxidation of sulfides ${ }^{37-44}$ or amines ${ }^{45,46}$ and BaeyerVilliger reactions. ${ }^{47,48}$ Recently, we developed an artificial enzyme by incorporating FMN inside a water soluble polyethyleneimine polymer functionalized with guanidinium and octyl groups (PElguanoct), and we demonstrated that NADH could reduce FMN into $\mathrm{FMNH}_{2}$ which was then able to deliver a single electron flow to redox cofactors (Scheme 1) such as manganese porphyrins ${ }^{49}$ or copper complexes. ${ }^{50}$ This artificial reductase (FMN-PEl guan-oct) was capable of reducing a functionalized $\mathrm{Mn}$ (III)-porphyrin that could then react with dioxygen in order to perform thioanisole oxidation, in low yields. In order to improve the catalytic efficiency of this system, we decided to replace the metalloporphyrin catalyst by polyoxometalates (POMs), a family of tunable, highly water-soluble and efficient catalysts for oxidation reactions. ${ }^{51-53}$ Although it has been shown that POMs could activate dioxygen, ${ }^{54,55}$ very few studies dedicated to oxidation catalysis in water-containing media have been reported so far. However, it is known that in acetic acid/water mixtures $\mathrm{H}_{3+\mathrm{x}} \mathrm{PV}_{\mathrm{x}} \mathrm{Mo}_{12-\mathrm{x}} \mathrm{O}_{40}(\mathrm{x}=1-6)$ can act as cocatalyst in several Pd" catalysed reactions. ${ }^{56}$ Also, in the same media, it has been shown that $\mathrm{H}_{3+\mathrm{x}} \mathrm{PV}_{\mathrm{x}} \mathrm{Mo}_{12-\mathrm{x}} \mathrm{O}_{40}$ could oxidize cyclohexanone in presence of $\mathrm{O}_{2}\left(T=70^{\circ} \mathrm{C}\right) .{ }^{57}$ Besides, it has been evidenced that when incorporated into a cationic polyethyleneimine-based polymer, the $\left[\left(\mathrm{ZnW}_{9} \mathrm{O}_{34}\right)_{2} \mathrm{WZn}_{3}\left(\mathrm{H}_{2} \mathrm{O}\right)_{2}\right]^{12-}$ POM was capable of catalyzing the oxidation of sulfides and alkenes in water. Nonetheless, this system required hydrogen peroxide as oxidant. ${ }^{33}$ Thus, POM-incorporating oxidative catalytic systems, working in pure water, at room temperature and with dioxygen as oxidant under atmospheric pressure, remain to be developed. Herein, we report for the first time a system where polyoxometalate catalysts have been combined in solution with an artificial reductase (FMN-PEl guan-oct) in the presence of NADH as a source of electrons for the reductive activation of dioxygen. Four different POMs, including two polyoxotungstates and two polyoxomolybdates, have been selected. The catalytic activity for the aerobic sulfoxidation reaction of the elaborated systems was studied, and the involved mechanisms were investigated.

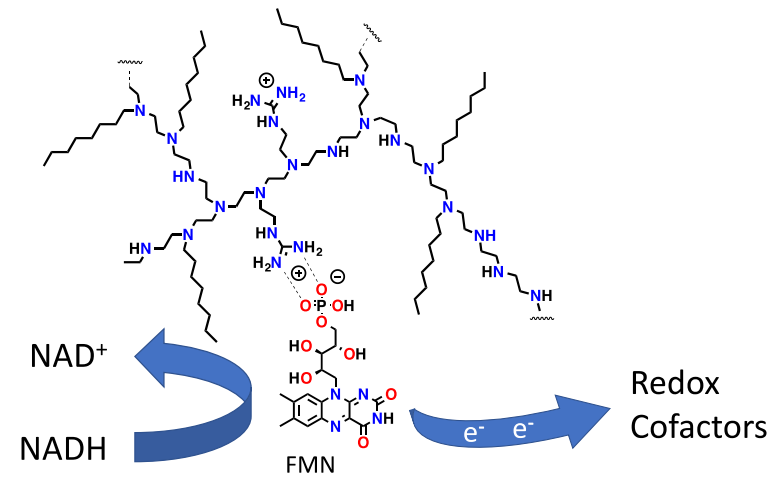

Scheme 1. Schematic representation of an artificial flavo-reductase (FMN PEl guan-oct) made of FMN incorporated into a water-soluble PEI modified with guanidinium and octyl groups.

\section{Experimental}

The series of water soluble Keggin type polyoxometalates based on low-toxic non-noble metals, namely $\left.\mathrm{Na}_{12}\left[\left(\mathrm{ZnW}_{9} \mathrm{O}_{34}\right)_{2} \mathrm{WZn}_{3}\left(\mathrm{H}_{2} \mathrm{O}\right)_{2}\right] \cdot 46 \mathrm{H}_{2} \mathrm{O} \quad\left(\mathrm{Zn}_{\mathbf{5}} \mathbf{W}_{\mathbf{1 9}}\right)\right)^{58}$ $\mathrm{H}_{3}\left[\mathrm{PMo}_{12} \mathrm{O}_{40}\right] \cdot 14 \mathrm{H}_{2} \mathrm{O}\left(\mathbf{P M O}_{12}\right),{ }^{59} \mathrm{H}_{4}\left[\mathrm{PMo}_{11} \mathrm{VO}_{40}\right] \cdot 14 \mathrm{H}_{2} \mathrm{O} \quad\left(\mathbf{P M O}_{11} \mathbf{V}\right){ }^{60}$ and $\mathrm{Na}_{7} \mathrm{~K}_{7}\left[\left\{\left(\mathrm{PW}_{9} \mathrm{O}_{34}\right) \mathrm{Ni}_{3}(\mathrm{OH})\left(\mathrm{H}_{2} \mathrm{O}\right)_{2}(\mathrm{Ale})\right\}_{2} \mathrm{Ni}\right] \cdot 34 \mathrm{H}_{2} \mathrm{O}\left(\mathbf{N i}_{7} \mathbf{W}_{\mathbf{1 8}}\right.$, Ale = alendronate $\left.=\left[\mathrm{O}_{3} \mathrm{PC}(\mathrm{O})\left(\mathrm{C}_{3} \mathrm{H}_{6} \mathrm{NH}_{3}\right) \mathrm{PO}_{3}\right]^{4-}\right)^{61}$ (Fig. $\mathrm{S} 1, \mathrm{ESI}+$ ) has been synthesized following reported procedures. Besides, a polyethyleneimine polymer modified with guanidinium and octyl groups (PEI guan-oct) was prepared by successive additions of praxadine and iodooctane to a DMF solution of $25 \mathrm{kDa}$ multibranched polyethyleneimine as previously described. ${ }^{62,63}$ The modified polymer was then purified by extensive dialysis to obtain an aqueous solution of $\mathrm{PEI}_{\text {guan-oct }}$ that was directly used for catalysis. The proportion of guanidinium and octyl groups grafted to the polymer were determined by ${ }^{1} \mathrm{H}$ NMR after lyophilization of the aqueous solution. ${ }^{64}$ Alternatively, the commercial multibranched 25 $\mathrm{kDa} \mathrm{PEI}$ was also used for comparison with the modified one. Catalytic experiments were performed in tinted glass vials in order to avoid any photochemical side reaction with the photosensitive flavin cofactor. In a typical experiment, $\mathrm{PEI}_{\text {guan-oct }}(2.5 \mathrm{mM}), \mathrm{FMN}$ (0.1 mM), POM (0.1 mM), the substrate (10 mM) and NADH (1 mM) were dissolved in deionized water (final volume $1 \mathrm{~mL}$ ) and left under stirring, under 1 atmosphere of dioxygen, for 16 hours. The resulting solution was then transferred into $8 \mathrm{~mL}$ of acetonitrile, dried over magnesium sulfate, filtrated on silica gel and analyzed by gas chromatography (GC) in the presence of an internal standard (Table S1, ESIt). It is worth to note that the product of the reaction may also be isolated by ethyl acetate extraction of the aqueous solution. However, this technique was not chosen for GC quantification because it was demonstrated to be less quantitatively reliable than the above described drowning technique.

\section{Results and discussion}

\section{Reactivity with POM $\mathrm{Zn}_{5} \mathrm{~W}_{19}$}

Since $\mathbf{Z} \mathbf{n}_{5} \mathbf{W}_{19}$ was previously used in the literature in combination with modified PEI and hydrogen peroxide to catalyze the oxidation of various small organic molecules, ${ }^{33}$ we first focused our attention on studying its reactivity in the presence of the FMN-PEI guan-oct$\mathrm{NADH}$. Control reactions involving different components were first performed using thioanisole as a substrate and the results are gathered in Table 1. All control experiments performed with a single reactant or binary combinations of reactants, e.g. NADH, FMN, $\mathrm{PEI}_{\text {guan-oct }}$ and/or $\mathbf{Z} \mathbf{n}_{\mathbf{5}} \mathbf{W}_{\mathbf{1 9}}$, showed no product formation, in contrast to those performed with tertiary combinations of FMN and NADH, with either PEI or $\mathbf{Z} \mathbf{n}_{\mathbf{5}} \mathbf{W}_{\mathbf{1 9}}$. The combination of PEI, FMN and NADH gave a $11 \%$ yield in sulfoxide with respect to NADH after 16 hours of reaction. This was not unexpected since the FMN, buried into the microenvironment of the PEI, had already been shown to be able to activate dioxygen to perform the Baeyer-Villiger oxidation. ${ }^{64}$ The combination of $\mathbf{Z} \mathbf{n}_{5} \mathbf{W}_{\mathbf{1 9}}, \mathrm{FMN}$ and $\mathrm{NADH}$ gave a $40 \%$ yield in sulfoxide after 16 hours of reaction. The same result was also found for the FMN/PEI guan-oct $/ \mathbf{Z n}_{5} \mathbf{W}_{19} / \mathrm{NADH}$ full system. This was more surprising since it was previously demonstrated that in absence of 
the modified polymer, NADH could not efficiently reduce the FMN ${ }^{49}$ This point will be discussed below in a paragraph dedicated to mechanistic studies. Finally, it is also worth to note that control reactions performed with the full system but in the absence of dioxygen only gave traces of sulfoxide, clearly demonstrating the aerobic character of the sulfoxidation process. These product traces may be explained by the difficulty to fully degas aqueous solutions, even by using freeze-pump techniques.

Table 1. Aerobic oxidation of thioanisole in the presence of the various components of the catalytic system in deionized water.

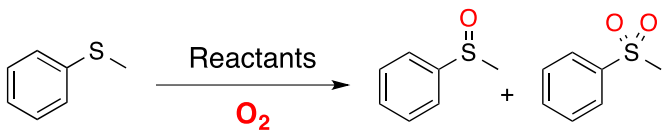

\begin{tabular}{|c|c|c|}
\hline \multirow{2}{*}{ Reactants } & \multicolumn{2}{|c|}{ Yield (\%) } \\
\hline & Sulfoxide & Sulfone \\
\hline $\mathrm{NADH}$ & $0( \pm 0)^{(a)}$ & $0( \pm 0)^{(a)}$ \\
\hline $\mathrm{NADH}+\mathbf{Z n}_{5} \mathbf{W}_{19}$ & $0( \pm 0)^{(a)}$ & $0( \pm 0)^{(a)}$ \\
\hline $\mathrm{NADH}+\mathrm{FMN}$ & $0( \pm 0)^{(a)}$ & $0( \pm 0)^{(a)}$ \\
\hline \multirow[t]{2}{*}{$\mathrm{NADH}+\mathrm{PEI}_{\text {guan-oct }}+\mathbf{Z n}_{\mathbf{5}} \mathbf{W}_{19}$} & $0( \pm 0)^{(a)}$ & $0( \pm 0)^{(a)}$ \\
\hline & $5( \pm 3)^{(b)}$ & $0( \pm 0)^{(b)}$ \\
\hline $\mathrm{NADH}+\mathrm{PEI}_{\text {guan-oct }}+\mathrm{FMN}$ & $11( \pm 6)^{(a)}$ & $0( \pm 0)^{(a)}$ \\
\hline \multirow[t]{2}{*}{$\mathrm{NADH}+\mathrm{FMN}+\mathbf{Z n}_{5} \mathbf{W}_{19}$} & $40( \pm 2)^{(a)}$ & $0( \pm 0)^{(a)}$ \\
\hline & $82( \pm 3)^{(b)}$ & $14( \pm 7)^{(b)}$ \\
\hline \multirow[t]{2}{*}{$\mathrm{NADH}+\mathrm{PEI}_{\text {guan-oct }}+\mathrm{FMN}+\mathbf{Z n}_{\mathbf{5}} \mathbf{W}_{19}$} & $40( \pm 5)^{(a)}$ & $0( \pm 0)^{(a)}$ \\
\hline & $75( \pm 2)^{(b)}$ & $9( \pm 6)^{(b)}$ \\
\hline
\end{tabular}

Yields of sulfoxide and sulfone calculated with respect to the amount of NAD introduced in the solution and analyzed by GC. Conditions: $[\mathrm{NADH}]=1 \mathrm{mM}$; $\left[\mathrm{Zn}_{5} \mathbf{W}_{19}\right]=0.1 \mathrm{mM} ;[\mathrm{FMN}]=0.1 \mathrm{mM} ;[$ PEl guan-oct $]=2.5 \mathrm{mM}$; $[$ thioanisole $]=10 \mathrm{mM}$ at room temperature, $\mathrm{Po}_{2}=1 \mathrm{~atm}$., for (a) $16 \mathrm{~h}$ and (b) $72 \mathrm{~h}$. Control experiments with the full system but in the absence of $\mathrm{O}_{2}$ only gave traces of sulfoxide.

Fig. 1 shows the yield for oxidation of thioanisole in water, under 1 atmosphere of $\mathrm{O}_{2}$ at room temperature, as a function of time for 72 hours of reaction. When $\mathbf{Z n}_{\mathbf{5}} \mathbf{W}_{\mathbf{1 9}}$ was combined to $\mathrm{FMN}-\mathrm{PEI_{ \text {guan-oct } }}$ and $\mathrm{NADH}$, the sulfoxide and the sulfone were respectively formed in $75 \%$ and $9 \%$ yields with respect to the amount of NADH added to the solution. Under the same conditions, but in the absence of polymer, the kinetics was very similar and the final yields, $82 \%$ in sulfoxide and $14 \%$ in sulfone respectively, were even slightly better. However, the control reaction in the absence of FMN, gave less than $5 \%$ yield in sulfoxide after 72 hours of reaction. In order to better understand why catalysis was efficient even in the absence of polymer, we measured the reduction of $0.1 \mathrm{mM} F M N$ by $1 \mathrm{mM}$ $\mathrm{NADH}$ under the above-mentioned conditions and one could observe that the FMN was reduced with a similar rate both in the presence and in the absence of $2.5 \mathrm{mM}$ polymer (Fig. S2, ESI + ). This is clearly different from previous data obtained at lower concentrations of FMN $(0.05 \mathrm{mM})$ and $\mathrm{NADH}(0.5 \mathrm{mM})$ for which the FMN needed to be incorporated into the PEI guan-oct $(1.25 \mathrm{mM})$ in order to be reduced. ${ }^{49}$ This concentration depending behavior could explain why the presence of FMN, NADH and $\mathbf{Z n}_{5} \mathbf{W}_{19}$ is enough to perform catalysis in good yield since the reduced FMN can activate dioxygen and produce $\mathrm{H}_{2} \mathrm{O}_{2}$ that is then used as an oxidant by $\mathbf{Z n}_{5} \mathbf{W}_{19}$ to perform the reaction. The formation of hydrogen peroxide was indeed demonstrated under both conditions using Quantofix peroxide test sticks. Interestingly, this $\mathrm{H}_{2} \mathrm{O}_{2}$ concentration was shown to be stable in the absence of substrate, meaning that $\mathrm{Zn}_{5} \mathbf{W}_{19}$ did not react with $\mathrm{H}_{2} \mathrm{O}_{2}$ or simply formed a stable $\mathbf{Z n}_{\mathbf{5}} \mathbf{W}_{\mathbf{1 9}} \mathrm{-OOH}$ hydroperoxo species if no substrate was available (see below).

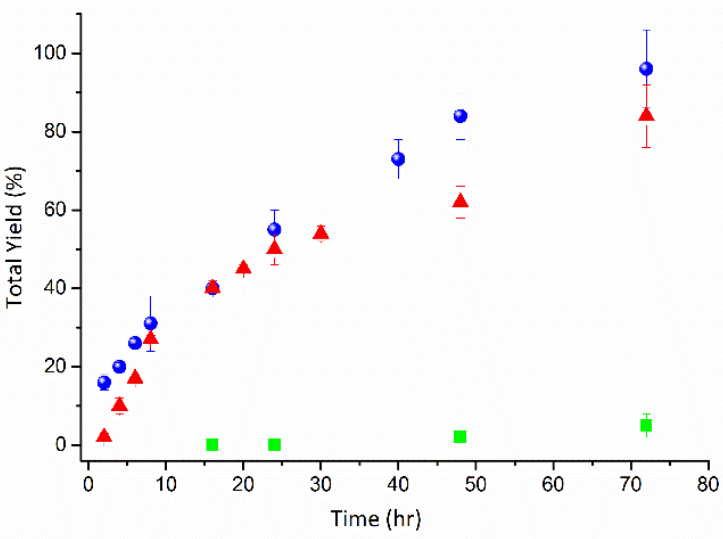

Fig. 1. Time course for the catalytic oxidation of thioanisole into sulfoxide and sulfone in the presence of $0.1 \mathrm{mM}$ POM $\mathrm{Zn}_{5} \mathbf{W}_{19}, 0.1 \mathrm{mM} F M N, 10 \mathrm{mM}$ thioanisole and $1 \mathrm{mM} \mathrm{NADH}$ with (red triangles) and without (blue circles)

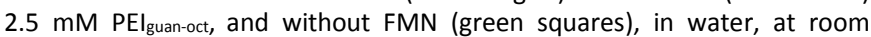
temperature and under $\mathrm{PO}_{2}=1 \mathrm{~atm}$.

Conversely, as soon as thioanisole was introduced in the solution, the $\mathrm{H}_{2} \mathrm{O}_{2}$ produced from $\mathrm{O}_{2}$ was consumed in the presence of $\mathbf{Z n}_{5} \mathbf{W}_{19}$ (Fig. 2). The stability of $\mathbf{Z} \mathbf{n}_{5} \mathbf{W}_{19}$ under the considered experimental conditions was studied. The POM was isolated from the catalytic medium by addition of cesium chloride before and after the catalytic event (see ESIt for details). First, a comparison of the IR spectrum of pristine $\mathbf{Z n}_{\mathbf{5}} \mathbf{W}_{\mathbf{1 9}}$ with that of the powder isolated from the reacting medium before the catalytic event evidenced that the POM was stable in aqueous solution in the presence of NADH, FMN and PEI guan-oct (Fig. S3, ESI + ). Second, it appeared that the POM isolated from the same reacting medium but after addition of thioanisole and stirring at room temperature for $16 \mathrm{~h}$ presented exactly the same IR features than those of the POM isolated before catalysis (Fig. S3, ESIt). This strongly suggested that $\mathbf{Z n}_{5} \mathbf{W}_{\mathbf{1 9}}$ was stable throughout the catalytic process, which was confirmed by EDX measurements on the recovered catalyst $(\mathrm{W}: \mathrm{Zn}$ ratio : theoretical $19: 5$, experimental $19: 6.1$ ). This is also supported by recyclability experiments, which show a steady increase in sulfoxide and sulfone after three successive injections of NADH at 0,24 and $48 \mathrm{~h}$ of reaction (Fig. S4, ESI+). It is also noteworthy that under such conditions, the formation of Ishii-Venturello complexes can be excluded, as such species only form in the presence of large amounts of $\mathrm{H}_{2} \mathrm{O}_{2}{ }^{65}$ whereas, on the contrary, under our conditions, $\mathrm{H}_{2} \mathrm{O}_{2}$ is produced in situ in low concentration and is readily consumed for the oxidation of the substrate. 
The mechanism presented in Scheme 2 can then be proposed. NADH first reduces the FMN whether it is incorporated into the polymer or not. However, the reduced $\mathrm{FMNH}_{2}$ does not reduce $\mathbf{Z n}_{5} \mathbf{W}_{19}$ as it could have been originally envisioned, but instead reacts with $\mathrm{O}_{2}$ to produce $\mathrm{H}_{2} \mathrm{O}_{2}$ in solution. The fact that $\mathrm{Zn}_{5} \mathbf{W}_{19}$ only consumes $\mathrm{H}_{2} \mathrm{O}_{2}$ in the presence of thioanisole suggests that $\mathbf{Z n}_{5} \mathbf{W}_{19}$ forms a hydroperoxo intermediate under such conditions. This intermediate then oxidizes thioanisole into methyl phenyl sulfoxide.

The scope of the reaction was then extended to substrates bearing various substituents on the para position of thioanisole (Table 2). Electron donating groups such as methyl did not affect the yield of the reaction with ca. $55 \%$ yield after 30 hours for both thioanisole and 4-methyl-thioanisole. Mesomeric donating groups such as methoxy improved the yield up to $65 \%$ while attracting mesomeric groups such as nitro gave no product at all. This clearly identified the nucleophilic activity of thioanisole for its reaction with the proposed $\mathbf{Z n}_{5} \mathbf{W}_{19}-\mathrm{OOH}$ intermediate. Finally, the surprising good reactivity of the para-bromo substituted thioanisole could be explained by the fact that, in this case, the mesomeric donating activity clearly overcomes the electron withdrawing activity of the bromide substituent.

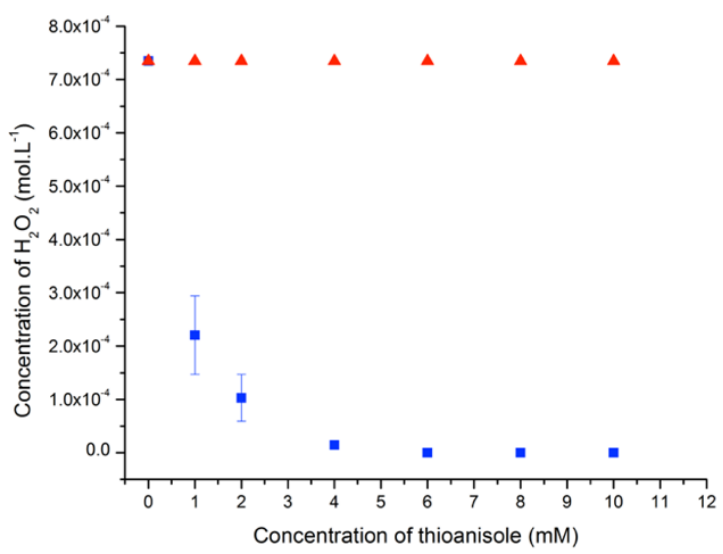

Fig. 2. $\mathrm{H}_{2} \mathrm{O}_{2}$ concentrations measured after 6 hours of reaction under aerobic conditions in the presence of 0 to $10 \mathrm{mM}$ thioanisole and of $2.5 \mathrm{mM}$ PElguan-oct, $0.1 \mathrm{mM} \mathrm{FMN}$ and $1 \mathrm{mM} \mathrm{NADH}$ with (blue squares) and without 0.1

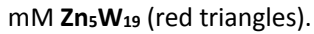

Table 2. Aerobic oxidation of various thioethers catalyzed by $\mathbf{Z n}_{\mathbf{5}} \mathbf{W}_{\mathbf{1 9}}$ and FMN-PEl guan-oct by using $\mathrm{NADH}$ and $\mathrm{O}_{2}$ in water.

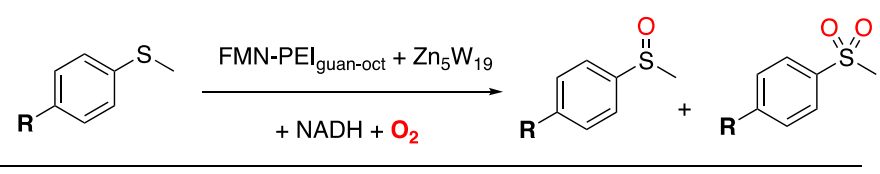

\begin{tabular}{lcc}
\hline \multicolumn{1}{c}{ Substrates } & \multicolumn{2}{c}{ Yield (\%) $^{\mathrm{a}}$} \\
& Sulfoxide & Sulfone \\
\hline $\mathbf{R}=\mathrm{H}$ & $54( \pm 2)$ & $0( \pm 0)$ \\
$\mathbf{R}=\mathrm{Me}$ & $55( \pm 6)$ & $0( \pm 0)$ \\
$\mathbf{R}=\mathrm{OMe}$ & $65( \pm 1)$ & $0( \pm 0)$
\end{tabular}
$\mathbf{R}=\mathrm{Br}$
$60( \pm 1)$
$0( \pm 0)$
$\mathbf{R}=\mathrm{NO}_{2}$
$0( \pm 0)$
$0( \pm 0)$

(a) Yields of sulfoxide and sulfone formed with respect to the amount of NADH introduced in $1 \mathrm{~mL}$ aqueous solution and analyzed by GC. Conditions: $[\mathrm{NADH}]=1 \mathrm{mM}$; $\left[\mathrm{Zn}_{5} \mathbf{W}_{19}\right]=0.1 \mathrm{mM} ;[\mathrm{FMN}]=0.1 \mathrm{mM} ;\left[\mathrm{PEI}_{\text {guan-oct }}\right]=2.5 \mathrm{mM}$; $[$ substrate $]=10 \mathrm{mM}$ at room temperature, under $\mathrm{PO}_{2}=1 \mathrm{~atm}$., reaction time: $30 \mathrm{~h}$.

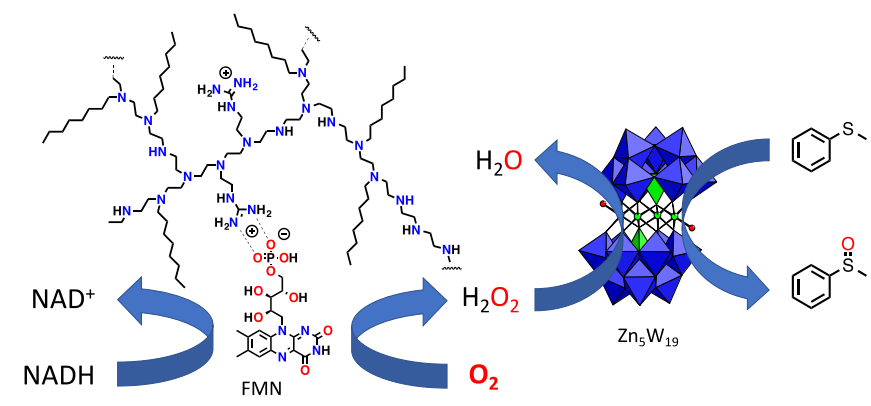

Scheme 2. Proposed reaction scheme for the oxidation of thioanisole by $\mathbf{Z n}_{\mathbf{5}} \mathbf{W}_{19}$ and $\mathrm{FMN}-\left.\mathrm{PE}\right|_{\text {guan-oct }}$ in the presence of NADH.

\section{Comparison of reactivity with three other POMs}

The catalytic oxidation of thioanisole was also studied with other POMs, the molybdenum POM $\mathbf{P M o}_{12}$, the molybdenum/vanadium POM $\mathbf{P M o}_{11} \mathbf{V}$ and the tungsten/nickel POM Ni7 $\mathbf{W}_{18}$ (Fig. S1, ESI + ). For the sake of comparison, the activities of the various POMs were studied either in the presence of the modified polymer ( $\mathrm{PEI}_{\text {guan-oct }}$ ) or in the presence of the commercial one $\left(\mathrm{PEI}_{\mathrm{com}}\right)$. The obtained data are listed in Table 3.

Table 3. Aerobic oxidation of thioanisole by various POMs in the presence of $\mathrm{NADH}$ and $\mathrm{O}_{2}$ and using FMN alone or incorporated into $\mathrm{PEI}_{\text {guan-oct }}$ or $\mathrm{PEI}_{\text {com. }}$.

\begin{tabular}{cccc}
\hline POMs & $\begin{array}{c}\text { Yield (\%) } \\
\text { with PEI }\end{array}$ & $\begin{array}{c}\text { Yield (\%)-oct } \\
\text { with PEI }\end{array}$ & $\begin{array}{c}\text { Yield (\%) } \\
\text { without PEI }\end{array}$ \\
\hline Zn $_{5} W_{19}$ & $50( \pm 4)$ & $63( \pm 2)$ & $55( \pm 5)$ \\
PMo $_{12}$ & $51( \pm 7)$ & $0( \pm 0)$ & $1.5( \pm 1)$ \\
PMo $_{11} V$ & $40( \pm 7)$ & $0( \pm 0)$ & $5( \pm 1)$ \\
Nit $_{18}$ & $45( \pm 5)$ & $23( \pm 4)$ & $8( \pm 1)$
\end{tabular}

(a) Yields of sulfoxide and sulfone formed with respect to the amount of NADH introduced in aqueous solution and analyzed by GC. Conditions: $[\mathrm{NADH}]=1 \mathrm{mM}$; $[\mathrm{POM}]=0.1 \mathrm{mM} ;[\mathrm{FMN}]=0.1 \mathrm{mM} ;\left[\mathrm{PEI}_{\text {guan-oct }}\right]$ or $\left[\mathrm{PEI}_{\text {com }}\right]=2.5 \mathrm{mM}$; [thioanisole $]=10$ $\mathrm{mM}$, at room temperature, under $\mathrm{Po}_{2}=1$ atm., reaction time $24 \mathrm{~h}$.

For all POMs, when the FMN was incorporated into the modified polymer, solely the corresponding sulfoxide was observed after 24 hours of reaction, with yields measured between 40 and $51 \%$. Interestingly, when the FMN was associated to the commercial PEI, the differences in yields were much larger, ranging from $0 \%$ for $\mathbf{P M O}_{12}$ and $\mathbf{P} \mathbf{M o}_{11} \mathbf{V}$ to $63 \%$ for $\mathbf{Z n}_{\mathbf{5}} \mathbf{W}_{\mathbf{1 9}}$. With $\mathbf{Z n}_{\mathbf{5}} \mathbf{W}_{\mathbf{1 9}}$, the yield in sulfoxide is thus rather high after $24 \mathrm{~h}$ of reaction in the absence of polymer, which confirms that the association of this POM with the polymer does not influence its reactivity for sulfoxidation at these 
concentrations. On the contrary, $\mathbf{P M o}_{12}$ and $\mathbf{P M o}_{11} \mathbf{V}$ only present significant catalytic activities when they are associated to $\mathrm{PEI}_{\text {guan-oct. }}$ Such effect of the local microenvironment provided by the polymer was previously observed for other metal catalyzed reactions such as phosphate transesterification reactions. ${ }^{63}$ As expected, the IR spectra of these species isolated from the aqueous medium $(\mathrm{pH}=$ 5.3) before the catalytic event revealed the presence of a mixture of phosphomolybdate species, as evidenced by the splitting of the P-O band found at $1057 \mathrm{~cm}^{-1}$ for $\mathbf{P M o}_{12}$ and $\mathbf{P M o}_{11} \mathbf{V}$ (Fig. S5, ESI ${ }^{+}$). However, the IR spectra of the POMs isolated before and after the catalytic processes are strictly similar, evidencing no evolution of the system during the oxidation of the substrate (Fig. S5, ESI+). Besides, since it was previously shown that, even in the absence of POM, $\mathrm{H}_{2} \mathrm{O}_{2}$ was produced by the system, the difference of reactivity between the phosphomolybdate and the phosphotungstate species should be related to an event prior to the formation of $\mathrm{H}_{2} \mathrm{O}_{2}$. There are, a priori, two hypotheses to explain the catalytic oxidation of thioanisole by the considered POM catalysts: (i) the reduced FMN reacts with $\mathrm{O}_{2}$ to generate $\mathrm{H}_{2} \mathrm{O}_{2}$ which then reacts with the POM catalyst, as it was observed for $\mathbf{Z} \mathbf{n}_{5} \mathbf{W}_{\mathbf{1 9}}$, or, (ii) the reduced $\mathrm{FMN}$ is directly reducing the POM which then performs the reductive activation of dioxygen as originally envisioned in Scheme 1. Importantly, as soon as NADH was added to a solution of FMN-PEI containing $\mathbf{P M O}_{12}$ and $\mathbf{P M o}_{11} \mathbf{V}$, the pale-yellow solutions turned green, suggesting the reduction of $\mathrm{Mo}^{\mathrm{VI}}$ centres. This reduction was confirmed by UV-Visible spectroscopy, with the appearance of a band characteristic of reduced POM heteropolyblues (Fig. 3a and S6, ESIT). ${ }^{66}$ One may note that the position of the band $(710 \mathrm{~nm})$ coincides with that observed for the $\alpha-\mathrm{IV}_{\mathrm{PMO}} \mathrm{PM}_{12}$ four-electron reduced species. ${ }^{67}$ Conversely, the simple use of NADH in solution, without FMN, did not allow the reduction of molybdenum centres (Fig. 3b).
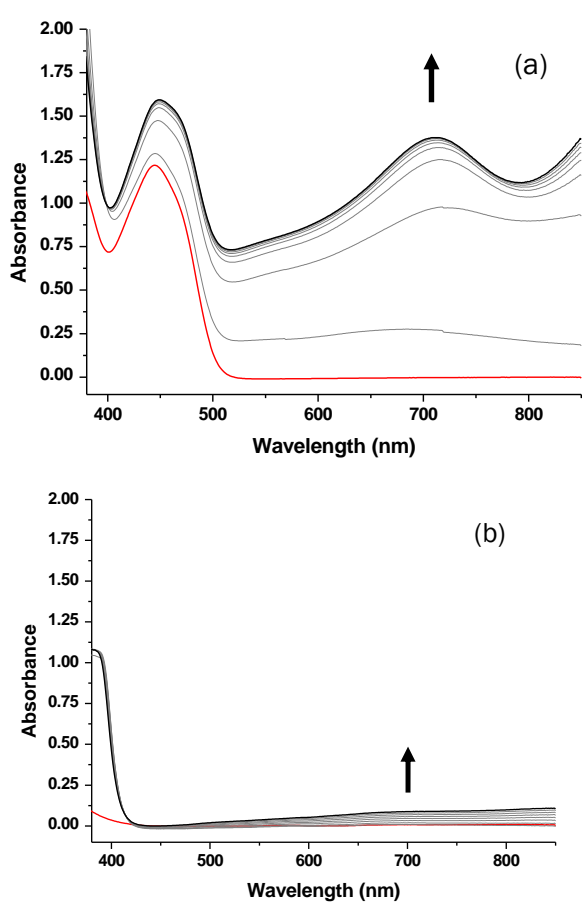

Fig. 3. UV-Visible spectra of aqueous solutions of (a) $\mathbf{P M o}_{12}(0.1 \mathrm{mM})$ and FMN (0.1 mM) followed for $16 \mathrm{~min}$. after addition of NADH (1 mM) and (b)
PMo $_{12}(0.1 \mathrm{mM})$ followed for $16 \mathrm{~min}$. after addition of NADH (1 mM). All experiments have been performed under anaerobic conditions.

It is worth to note that the reduction of $\mathrm{Mo}(\mathrm{VI})$ in the case of $\mathbf{P M O}_{11} \mathbf{V}$ implies that $\mathrm{V}(\mathrm{V})$ was also reduced since its reduction potential is lower than the one of $\mathrm{Mo}(\mathrm{VI})$. Besides, by following the variations with time of the absorbance at $710 \mathrm{~nm}$ in the presence of FMN-PEl guan-oct and FMN-PEI, respectively, it can be observed that the reduction of $\mathbf{P M O}_{12}$ is more efficient using the artificial reductase based on the modified polymer, FMN-PEl guan-oct (Fig. S7, ESI + ). Clearly, under such conditions, the reduced POM better activates $\mathrm{O}_{2}$, which reinforces the hypothesis that the catalytic event could indeed first involve the reduction of the POM, followed by the reductive activation of dioxygen. All these observations lead to the proposed mechanism presented in Scheme 3. We can note that the difference in mechanism observed for $\mathbf{Z n}_{5} \mathbf{W}_{19}$ and $\mathbf{P M O}_{12}$ agrees with the fact that polyoxomolybdates are by far more easily reduced than polyoxotungstates. ${ }^{68}$

As mentioned above, the catalytic activity of $\mathbf{Z} \mathbf{n}_{5} \mathbf{W}_{19}$ is similar using PEl guan-oct and $\mathrm{PEI}_{\text {com }}$ while $\mathbf{P M O}_{12}$ and $\mathbf{P M O}_{11} \mathbf{V}$ only oxidize thioanisole in presence of $\mathrm{PEI}_{\text {guan-oct. We have investigated a second }}$ polyoxotungstate, the $\mathbf{N i}_{7} \mathbf{W}_{\mathbf{1 8}}$ nickel complex $\mathrm{Na}_{7} \mathrm{~K}_{7}\left[\left\{\left(\mathrm{PW}_{9} \mathrm{O}_{34}\right) \mathrm{Ni}_{3}(\mathrm{OH})\left(\mathrm{H}_{2} \mathrm{O}\right)_{2}(\mathrm{Ale})\right\}_{2} \mathrm{Ni}\right] \cdot 34 \mathrm{H}_{2} \mathrm{O}$. It has been evidenced that $\mathbf{N i}_{7} \mathbf{W}_{\mathbf{1 8}}$ exhibited an intermediate catalytic behavior, showing the richness of the present system. Indeed, while the yield in oxidized products is higher with PEl guan-oct, this POM is also significantly active with $\mathrm{PEI}_{\text {com }}$ (see Table 3 ). Finally, as for $\mathbf{Z n}_{\mathbf{5}} \mathbf{W}_{\mathbf{1 9}}$, IR characterization of the POM before and after the catalytic event (Fig. S8, ESI') strongly suggests that this POM is stable under the considered catalytic conditions.

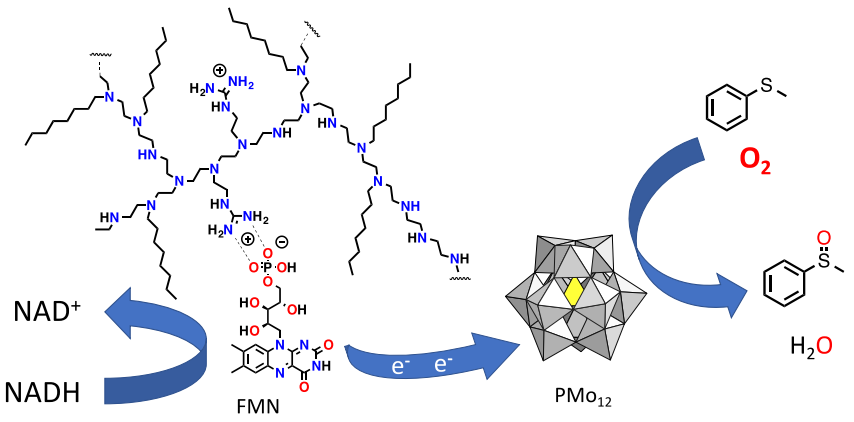

Scheme 3. Proposed reaction scheme for the oxidation of thioanisole by $\mathrm{PMO}_{12}$ and $\mathrm{FMN}-\mathrm{PEI}_{\text {guan-oct }}$ in the presence of NADH.

\section{Conclusions}

The activity of polyoxomolybdates and polyoxotungstates in combination with an artificial reductase and NADH has been studied for the aerobic oxidation of thioanisole derivatives. All POMs have demonstrated a catalytic activity in the presence of the artificial reductase under atmospheric pressure, in water and at room temperature. To the best of our knowledge, this represents the first evidence of a sulfoxidation activity for POMs under such mild conditions. Importantly, the obtained 
yields are comparable or even higher for cheap one-step and large-scale synthesized POMs such as $\mathrm{Na}_{12}\left[\left(\mathrm{ZnW}_{9} \mathrm{O}_{34}\right)_{2} \mathrm{WZn}_{3}\left(\mathrm{H}_{2} \mathrm{O}\right)_{2}\right] \cdot 46 \mathrm{H}_{2} \mathrm{O}$ or $\mathrm{H}_{3}\left[\mathrm{PMo}_{12} \mathrm{O}_{40}\right] \cdot 14 \mathrm{H}_{2} \mathrm{O}$ than those previously reported for the manganese(III)-mesotetra(pentafluorophenyl)porphyrin,

known as one of the best metalloporphyrin-based catalyst for oxidation reactions. ${ }^{49}$ Two different mechanisms have been brought out. In the case of $\mathrm{Na}_{12}\left[\left(\mathrm{ZnW}_{9} \mathrm{O}_{34}\right)_{2} \mathrm{WZn}_{3}\left(\mathrm{H}_{2} \mathrm{O}\right)_{2}\right] \cdot 46 \mathrm{H}_{2} \mathrm{O}$, the artificial reductase does not transfer electrons to the POM but instead reduces in situ $\mathrm{O}_{2}$ into $\mathrm{H}_{2} \mathrm{O}_{2}$ which then reacts with the inorganic anion to perform sulphide oxidation. We can note that the recyclability of the system was evidenced. Conversely, $\mathrm{H}_{3}\left[\mathrm{PMO}_{12} \mathrm{O}_{40}\right] \cdot 14 \mathrm{H}_{2} \mathrm{O}$ is reduced by the artificial reductase and can then catalyze itself the reductive activation of $\mathrm{O}_{2}$ to perform the sulfoxidation reaction. Also, the investigated $\left[\mathrm{PMo}_{11} \mathrm{VO}_{40}\right]^{4-}$ species appeared to react similarly to $\left[\mathrm{PMo}_{12} \mathrm{O}_{40}\right]^{3-}$. Now, considering the tremendous wide range of applications of POMs in oxidation catalysis, we are considering extending this study to other reactions, in particular the oxidation of alkenes and alkanes.

\section{Conflicts of interest}

There are no conflicts to declare.

\section{Acknowledgements}

This work was supported by the Ministère de l'Enseignement Supérieur et de la Recherche, the CNRS, the Université de Versailles Saint Quentin en Yvelines, the Université Paris-Sud, The University Paris Saclay and a public grant overseen by the French National Research Agency (ANR) as part of the "Investissements d'Avenir" program nANR-11-IDEX-0003-02 and CHARMMMAT ANR-11-LABEX-0039.

\section{Notes and references}

1 K. Orloff and H. Falk, An international perspective on hazardous waste practices, Int. J. Hyg. Environ. Health, 2003, 206, 291-302.

2 R. A. Sheldon, Green and sustainable chemistry: challenges and perspectives, Green Chem., 2008, 10, 359-360.

3 B. M. Trost, On Inventing Reactions for Atom Economy, Acc. Chem. Res., 2002, 35, 695-705.

4 C. L. Hill, Controlled green oxidation, Nature, 1999, 401, 436.

5 G.-J. Deng, C.-J. Li, R. A. Sheldon and T. H. Chan, Synthetic Chemistry with an Eye on Future
Sustainability, 2012.

6 P. T. Anastas and J. C. Warner, Green Chemistry: Theory and Practice, Oxford University Press, 2000.

7 R. A. Sheldon, I. W. C. E. Arends and U. Hanefeld, Green Chemistry and Catalysis, Wiley-Blackwell, 2007.

8 K. A. Powell, S. W. Ramer, S. B. del Cardayré, W. P. C. Stemmer, M. B. Tobin, P. F. Longchamp and G. W. Huisman, Directed Evolution and Biocatalysis, Angew Chem Int Ed, 2001, 40, 3948-3959.

9 P. Berthouex and L. Brown, Oxidation-Reduction Reactions, CRC Press, 2018.

10 M. Rolff, J. Schottenheim, G. Peters and F. Tuczek, The First Catalytic Tyrosinase Model System Based on a Mononuclear Copper(I) Complex: Kinetics and Mechanism, Angew Chem Int Ed, 2010, 49, 6438-6442.

11 J. B. Metternich and R. Gilmour, A Bio-Inspired, Catalytic E $\rightarrow$ Z Isomerization of Activated Olefins, $J$. Am. Chem. Soc., 2015, 137, 11254-11257.

12 S. Caron, R. W. Dugger, S. G. Ruggeri, J. A. Ragan and D. H. B. Ripin, Large-Scale Oxidations in the Pharmaceutical Industry, Chem. Rev., 2006, 106, 29432989.

13 M. Madesclaire, Synthesis of sulfoxides by oxidation of thioethers, Tetrahedron, 1986, 42, 5459-5495.

14 E. G. Mata, RECENT ADVANCES IN THE SYNTHESIS OF SULFOXIDES FROM SULFIDES, Phosphorus Sulfur Silicon Relat. Elem., 1996, 117, 231286.

15 D. J. Procter, The synthesis of thiols, selenols, sulfides, selenides, sulfoxides, selenoxides, sulfones and selenones, J Chem Soc Perkin Trans 1, 1999, 641-668.

16 T. Punniyamurthy, S. Velusamy and J. Iqbal, Recent Advances in Transition Metal Catalyzed Oxidation of Organic Substrates with Molecular Oxygen, Chem. Rev., 2005, 105, 2329-2364.

17 Z. Shi, C. Zhang, C. Tang and N. Jiao, Recent advances in transition-metal catalyzed reactions using molecular oxygen as the oxidant, Chem Soc Rev, 2012, 41, 3381-3430. 
18 A. N. Campbell and S. S. Stahl, Overcoming the "Oxidant Problem": Strategies to Use $\mathrm{O}_{2}$ as the Oxidant in Organometallic C-H Oxidation Reactions Catalyzed by Pd (and Cu), Acc. Chem. Res., 2012, 45, 851-863.

19 E. C. Carson and S. J. Lippard, Oxidation of Sulfide, Phosphine, and Benzyl Substrates Tethered to N-Donor Pyridine Ligands in Carboxylate-Bridged Diiron(II) Complexes, J. Am. Chem. Soc., 2004, 126, 3412-3413.

20 B. J. Pistorio, C. J. Chang and D. G. Nocera, A Phototriggered Molecular Spring for Aerobic Catalytic Oxidation Reactions, J. Am. Chem. Soc., 2002, 124, 7884-7885.

21 N. M. Okun, T. M. Anderson and C. L. Hill, $\left[\left(\mathrm{Fe}^{\mathrm{III}}\left(\mathrm{OH}_{2}\right)_{2}\right)_{3}\left(\mathrm{~A}-\alpha-\mathrm{PW}_{9} \mathrm{O}_{34}\right)_{2}\right]^{9-}$ on Cationic Silica Nanoparticles, a New Type of Material and Efficient Heterogeneous Catalyst for Aerobic Oxidations, J. Am. Chem. Soc., 2003, 125, 3194-3195.

22 L. Que and R. Y. N. Ho, Dioxygen Activation by Enzymes with Mononuclear Non-Heme Iron Active Sites, Chem. Rev., 1996, 96, 2607-2624.

23 M. Merkx, D. A. Kopp, M. H. Sazinsky, J. L. Blazyk, J. Müller and S. J. Lippard, Dioxygen Activation and Methane Hydroxylation by Soluble Methane Monooxygenase: A Tale of Two Irons and Three Proteins, Angew Chem Int Ed, 2001, 40, 27822807.

24 B. Meunier, S. P. de Visser and S. Shaik, Mechanism of Oxidation Reactions Catalyzed by Cytochrome P450 Enzymes, Chem. Rev., 2004, 104, 3947-3980.

25 I. Schlichting, J. Berendzen, K. Chu, A. M. Stock, S. A. Maves, D. E. Benson, R. M. Sweet, D. Ringe, G. A. Petsko and S. G. Sligar, The Catalytic Pathway of Cytochrome P450cam at Atomic Resolution, Science, 2000, 287, 1615.

26 G. de Gonzalo, M. D. Mihovilovic and M. W. Fraaije, Recent Developments in the Application of Baeyer-Villiger Monooxygenases as Biocatalysts, ChemBioChem, 2010, 11, 2208-2231.

27 T. Iyanagi, C. Xia and J.-J. P. Kim, NADPHcytochrome P450 oxidoreductase: Prototypic member of the diflavin reductase family, Arch. Biochem. Biophys.,
2012, 528, 72-89.

28 E. Kaiser and D. Lawrence, Chemical mutation of enzyme active sites, Science, 1984, 226, 505.

29 S. S. Agasti, S. T. Caldwell, G. Cooke, B. J. Jordan, A. Kennedy, N. Kryvokhyzha, G. Rabani, S. Rana, A. Sanyal and V. M. Rotello, Dendron-based model systems for flavoenzyme activity: towards a new class of synthetic flavoenzyme, Chem. Commun., 2008, 4123-4125.

30 I. Tabushi and M. Kodera, Flavocyclodextrin as a promising flavoprotein model. Efficient electron transfer catalysis by flavocyclodextrin, J. Am. Chem. Soc., 1987, 109, 4734-4735.

31 J. B. Metternich and R. Gilmour, One Photocatalyst, n Activation Modes Strategy for Cascade Catalysis: Emulating Coumarin Biosynthesis with (-)-Riboflavin, J. Am. Chem. Soc., 2016, 138, 1040-1045.

32 M. C. Feiters, A. E. Rowan and R. J. M. Nolte, From simple to supramolecular cytochrome $\mathrm{P} 450$ mimics, Chem. Soc. Rev., 2000, 29, 375-384.

33 A. Haimov, H. Cohen and R. Neumann, Alkylated Polyethyleneimine/Polyoxometalate Synzymes as Catalysts for the Oxidation of Hydrophobic Substrates in Water with Hydrogen Peroxide, J. Am. Chem. Soc., 2004, 126, 11762-11763.

34 P. C. Cirino and F. H. Arnold, A Self-Sufficient Peroxide-Driven Hydroxylation Biocatalyst, Angew. Chem. Int. Ed., 2003, 42, 3299-3301.

35 P. C. Cirino and F. H. Arnold, Regioselectivity and Activity of Cytochrome P450 BM-3 and Mutant F87A in Reactions Driven by Hydrogen Peroxide, Adv. Synth. Catal., 2002, 344, 932-937.

36 P. Battioni, J. P. Renaud, J. F. Bartoli, M. ReinaArtiles, M. Fort and Daniel. Mansuy, Monooxygenaselike oxidation of hydrocarbons by hydrogen peroxide catalyzed by manganese porphyrins and imidazole: selection of the best catalytic system and nature of the active oxygen species, J. Am. Chem. Soc., 1988, 110, 8462-8470.

37 J. Zelenka, T. Hartman, K. Klímová, F. Hampl and 
R. Cibulka, Phase-Transfer Catalysis in Oxidations Based on the Covalent Bonding of Hydrogen Peroxide to Amphiphilic Flavinium Salts, ChemCatChem, 2014, 6, 2843-2846.

38 B. J. Marsh and D. R. Carbery, Chemoselective sulfide oxidation mediated by bridged flavinium organocatalysts, Tetrahedron Lett., 2010, 51, 23622365 .

39 J. Žurek, R. Cibulka, H. Dvořáková and J. Svoboda, $\mathrm{N}_{1}, \mathrm{~N}_{10}$-Ethylene-bridged flavinium salts derived from 1valinol: synthesis and catalytic activity in $\mathrm{H}_{2} \mathrm{O}_{2}$ oxidations, Tetrahedron Lett., 2010, 51, 1083-1086.

40 L. Baxová, R. Cibulka and F. Hampl,

Organocatalytic sulfoxidation in micellar systems containing amphiphilic flavinium salts using hydrogen peroxide as a terminal oxidant, J. Mol. Catal. Chem., 2007, 277, 53-60.

41 Y. Imada, T. Ohno and T. Naota, Oxidation of sulfides with hydrogen peroxide catalyzed by $10,10^{\prime}$ linked bisflavinium perchlorates, Tetrahedron Lett., 2007, 48, 937-939.

42 A. A. Lindén, N. Hermanns, S. Ott, L. Krüger and J.E. Bäckvall, Preparation and Redox Properties of N,N,N-1,3,5-Trialkylated Flavin Derivatives and Their Activity as Redox Catalysts, Chem. - Eur. J., 2004, 11, 112-119.

43 A. A. Lindén, L. Krüger and J.-E. Bäckvall, Highly Selective Sulfoxidation of Allylic and Vinylic Sulfides by Hydrogen Peroxide Using a Flavin as Catalyst, $J$. Org. Chem., 2003, 68, 5890-5896.

44 A. B. E. Minidis and J.-E. Bäckvall, Mild and Efficient Flavin-Catalyzed $\mathrm{H}_{2} \mathrm{O}_{2}$ Oxidations, Chem. Eur. J., 2001, 7, 297-302.

45 K. Bergstad and J.-E. Bäckvall, Mild and Efficient Flavin-Catalyzed $\mathrm{H}_{2} \mathrm{O}_{2}$ Oxidation of Tertiary Amines to Amine N-Oxides, J. Org. Chem., 1998, 63, 6650-6655.

46 S. Murahashi, T. Oda and Y. Masui, Flavincatalyzed oxidation of amines and sulfur compounds with hydrogen peroxide, J. Am. Chem. Soc., 1989, 111, 5002-5003.
47 S.-I. Murahashi, S. Ono and Y. Imada, Asymmetric Baeyer-Villiger Reaction with Hydrogen Peroxide Catalyzed by a Novel Planar-Chiral Bisflavin, Angew Chem Int Ed, 2002, 41, 2366-2368.

48 C. Mazzini, J. Lebreton and R. Furstoss, FlavinCatalyzed Baeyer-Villiger Reaction of Ketones: Oxidation of Cyclobutanones to $\gamma$ Lactones Using Hydrogen Peroxide, J. Org. Chem., 1996, 61, 8-9.

49 Y. Roux, R. Ricoux, F. Avenier and J.-P. Mahy, Bioinspired electron-delivering system for reductive activation of dioxygen at metal centres towards artificial flavoenzymes, Nat. Commun., 2015, 6, 8509.

50 K. Cheaib, Y. Roux, C. Herrero, A. Trehoux, F. Avenier and J.-P. Mahy, Reduction of a tris(picolyl)amine copper(ii) complex by a polymeric flavo-reductase model in water, Dalton Trans., 2016, 45, 18098-18101.

51 S. M. Lauinger, Q. Yin, Y. V. Geletii and C. L. Hill, in Advances in Inorganic Chemistry, eds. R. van Eldik and L. Cronin, Academic Press, 2017, vol. 69, pp. 117154.

52 S.-S. Wang and G.-Y. Yang, Recent Advances in Polyoxometalate-Catalyzed Reactions, Chem. Rev., 2015, 115, 4893-4962.

53 Streb Carsten, Kastner Katharina and Tucher Johannes, Polyoxometalates in photocatalysis, Phys. Sci. Rev., , DOI:10.1515/psr-2017-0177.

54 R. Neumann, Activation of Molecular Oxygen, Polyoxometalates, and Liquid-Phase Catalytic Oxidation, Inorg. Chem., 2010, 49, 3594-3601.

55 I. A. Weinstock, R. E. Schreiber and R. Neumann, Dioxygen in Polyoxometalate Mediated Reactions, Chem. Rev., 2018, 118, 2680-2717.

56 H. Goldberg, I. Kaminker, D. Goldfarb and R. Neumann, Oxidation of Carbon Monoxide Cocatalyzed by Palladium( $(0)$ and the $\mathrm{H}_{5} \mathrm{PV}_{2} \mathrm{Mo}_{10} \mathrm{O}_{40}$ Polyoxometalate Probed by Electron Paramagnetic Resonance and Aerobic Catalysis, Inorg. Chem., 2009, 48, 7947-7952.

57 F. Cavani, L. Ferroni, A. Frattini, C. Lucarelli, A. 
Mazzini, K. Raabova, S. Alini, P. Accorinti and P. Babini, Evidence for the presence of alternative mechanisms in the oxidation of cyclohexanone to adipic acid with oxygen, catalysed by Keggin polyoxometalates, Recent Dev. Model Catal. - Closing Gap Tech. Appl., 2011, 391, 118-124.

58 C. M. Tourné, G. F. Tourné and F. Zonnevijlle, Chiral polytungstometalates $\left[\mathrm{WM}_{3}\left(\mathrm{H}_{2} \mathrm{O}\right)_{2}\left(\mathrm{XW}_{9} \mathrm{O}_{34}\right)_{2}\right]^{12-}$ ( $\mathrm{X}=\mathrm{M}=\mathrm{Zn}$ or $\mathrm{Co}$ ) and their $\mathrm{M}$-substituted derivatives. Syntheses, chemical, structural and spectroscopic study of some D,L sodium and potassium salts, J Chem Soc Dalton Trans, 1991, 143-155.

59 E. O. North, W. Haney and J. C. Bailar Jr., in Inorganic Syntheses, John Wiley \& Sons, Ltd, 2007, pp. 127-129.

60 G. A. Tsigdinos and C. J. Hallada, Molybdovanadophosphoric acids and their salts. I. Investigation of methods of preparation and characterization, Inorg. Chem., 1968, 7, 437-441.

61 H. El Moll, G. Rousseau, A. Dolbecq, O. Oms, J. Marrot, M. Haouas, F. Taulelle, E. Rivière, W. Wernsdorfer, D. Lachkar, E. Lacôte, B. Keita and P. Mialane, Properties of a Tunable Multinuclear Nickel Polyoxotungstate Platform, Chem. - Eur. J., 2013, 19, 6753-6765.

62 F. Avenier, J. B. Domingos, L. D. Van Vliet and F. Hollfelder, Polyethylene Imine Derivatives ('Synzymes') Accelerate Phosphate Transfer in the Absence of Metal, J. Am. Chem. Soc., 2007, 129, 76117619.

63 F. Avenier and F. Hollfelder, Combining Medium Effects and Cofactor Catalysis: Metal-Coordinated Synzymes Accelerate Phosphate Transfer by 108, Chem. - Eur. J., 2009, 15, 12371-12380.

64 Y. Chevalier, Y. Lock Toy Ki, D. le Nouen, J.-P. Mahy, J.-P. Goddard and F. Avenier, Aerobic BaeyerVilliger Oxidation Catalyzed by a Flavin-Containing Enzyme Mimic in Water, Angew. Chem. Int. Ed., 2018, 57, 16412-16415.

65 C. Venturello, E. Alneri and M. Ricci, A new, effective catalytic system for epoxidation of olefins by hydrogen peroxide under phase-transfer conditions, $J$. Org. Chem., 1983, 48, 3831-3833.

66 A. M. Douvas, M. Vasilopoulou, D. G. Georgiadou, A. Soultati, D. Davazoglou, N. Vourdas, K. P. Giannakopoulos, A. G. Kontos, S. Kennou and P. Argitis, Sol-gel synthesized, low-temperature processed, reduced molybdenum peroxides for organic optoelectronics applications, J Mater Chem C, 2014, 2, 6290-6300.

67 D. Amitouche, M. Haouas, T. Mazari, S. Mouanni, R. Canioni, C. Rabia, E. Cadot and C. Marchal-Roch, The primary stages of polyoxomolybdate catalyzed cyclohexanone oxidation by hydrogen peroxide as investigated by in situ NMR. Substrate activation and evolution of the working catalyst, Appl. Catal. Gen., 2018, 561, 104-116.

68 M. Sadakane and E. Steckhan, Electrochemical Properties of Polyoxometalates as Electrocatalysts, Chem. Rev., 1998, 98, 219-238. 